\title{
Middle Cranial Fossa Sphenoidal Region Dural Arteriovenous Fistulas: Anatomic and Treatment Considerations
}

\author{
Z.-S. Shi, J. Ziegler, L. Feng, N.R. Gonzalez, S. Tateshima, R. Jahan, N.A. Martin, F. Viñuela, and G.R. Duckwiler
}

\section{ABSTRACT}

BACKGROUND AND PURPOSE: DAVFs rarely involve the sphenoid wings and middle cranial fossa. We characterize the angiographic findings, treatment, and outcome of DAVFs within the sphenoid wings.

MATERIALS AND METHODS: We reviewed the clinical and radiologic data of 11 patients with DAVFs within the sphenoid wing that were treated with an endovascular or with a combined endovascular and surgical approach.

RESULTS: Nine patients presented with ocular symptoms and 1 patient had a temporal parenchymal hematoma. Angiograms showed that 5 DAVFs were located on the lesser wing of sphenoid bone, whereas the other 6 were on the greater wing of the sphenoid bone. Multiple branches of the ICA and ECA supplied the lesions in 7 patients. Four patients had cortical venous reflux and 7 patients had varices. Eight patients were treated with transarterial embolization using liquid embolic agents, while 3 patients were treated with transvenous embolization with coils or in combination with Onyx. Surgical disconnection of the cortical veins was performed in 2 patients with incompletely occluded DAVFs. Anatomic cure was achieved in all patients. Eight patients had angiographic and clinical follow-up and none had recurrence of their lesions.

CONCLUSIONS: DAVFs may occur within the dura of the sphenoid wings and may often have a presentation similar to cavernous sinus DAVFs, but because of potential associations with the cerebral venous system, may pose a risk for intracranial hemorrhage. Curative embolization through a transarterial or transvenous approach is the primary therapeutic strategy for these lesions. In incompletely embolized patients, exclusion of any refluxing cortical veins is necessary.

ABBREVIATIONS: $\mathrm{DAVF}=$ dural arteriovenous fistula; $\mathrm{ECA}=$ external carotid artery; $\mathrm{GDC}=$ Guglielmi detachable coil; $\mathrm{MMA}=$ middle meningeal artery; $n$-BCA $=$ $n$-butyl cyanoacrylate; $S M C V=$ superficial middle cerebral vein; $S O V=$ superior ophthalmic vein

ntracranial DAVFs are sporadic pathologic arteriovenous connections that most commonly involve the wall of a major dural venous sinus. ${ }^{1}$ The sphenoid bone forms the foundation of the anterior and middle cranial fossae. It is a complex, centrally placed bone, through which critical neurovascular connections

Received October 29, 2010; accepted after revision March 23, 2012

From the Department of Neurosurgery (Z.-S.S.), The First Affiliated Hospital of Sun Yat-sen University, Guangzhou, China; Division of Interventional Neuroradiology (Z.-S.S., J.Z., L.F., N.R.G., S.T., R.J., G.R.D., F.V.) and Department of Neurosurgery (N.R.G., N.A.M.), David Geffen School of Medicine, University of California at Los Angeles, Los Angeles, California; Division of Interventional Neuroradiology (J.Z.), University of California at Irvine, Orange, California; Division of Diagnostic and Interventional Neuroradiology (J.Z.), Naval Medical Center, San Diego, California; Kaiser Foundation Hospital (J.Z.), San Diego, California; and Department of Diagnostic Imaging (L.F.), Kaiser Permanente Medical Center, Los Angeles, California

Zhong-Song Shi is supported by grants from the Program for New Century Excellent Talents in University of China (NCET2011), National Natural Science Foundation of China (81070949), and Fundamental Research Funds for Central Universities, Sun Yat-sen University (09ykpy38).

Please address correspondence to Gary R. Duckwiler, MD, Division of Interventional Neuroradiology, David Geffen School of Medicine at UCLA, 757 Westwood Plaza, Los Angeles, CA 90095-7437; e-mail: gduckwiler@mednet.ucla.edu are transmitted via vital foramina and fissures. A variation of small venous sinuses can be found along the lesser and greater wings of the sphenoid, which connect with emissary veins that pass through various foramina in parallel to the dural arteries, allowing for the development of complex DAVFs. DAVFs involving the sphenoid bone are rare entities that can be easily confused with other more common types of DAVFs in the middle cranial fossa, particularly cavernous sinus DAVFs.

Anecdotal reports of DAVFs involving the sphenoid bone can be found in the literature, with various nomenclature. ${ }^{2-18}$ Endovascular occlusion of these fistulous connections by transarterial or transvenous approaches is the primary therapeutic strategy for cure of these potentially dangerous lesions. Surgical disconnection of any recruited cortical draining veins may become necessary when embolization fails to eliminate the entire lesion. In this

\footnotetext{
- Indicates open access to non-subscribers at www.ajnr.org

= Indicates article with supplemental on-line tables.

http://dx.doi.org/10.3174/ajnr.A3193
} 
study, we describe the clinical presentation, angiographic findings, treatment, and outcomes of patients with DAVF with lesions of the sphenoid bone at a neurovascular center, with an emphasis on anatomy and treatment considerations.

\section{MATERIALS AND METHODS \\ Patient Population}

We retrospectively reviewed 323 consecutive patients with intracranial DAVFs treated at our institution between February 1991 and April 2010. The procedure reports of all patients with DAVFs and their respective digital subtraction angiograms were further reviewed, and 11 lesions clearly demonstrated a fistulous network involving the sphenoidal region of the middle cranial fossa.

This series includes 5 women and 6 men ranging from 29-78 years of age. Nine patients presented with eye symptoms, including proptosis, chemosis, diplopia, visual deterioration, hemianopsia, and retro-orbital pain. Three of these 9 patients had bruits. One patient suffered a temporal lobe hematoma. One patient had an incidental DAVF discovered during embolization of a traumatic carotid cavernous fistula. Three patients had a significant history of motor vehicle crashes. One patient had previously undergone an unsuccessful endovascular treatment at an outside hospital.

\section{Angiographic Anatomy}

Cerebral angiography was completed to identify any dural fistulas, and any associated arterial supply and venous drainage. Angiograms of the ICA, ECA, and vertebral artery were analyzed in detail. Superselective catheterization of the feeding arteries was performed to characterize the site of arteriovenous shunt surgery.

The patients in this series were found to have fistulas involving the greater or lesser wings of the sphenoid bone in the middle cranial fossa. There is controversy surrounding the nomenclature and anatomy at this level. Classically, the description is of a dural sinus at the lesser wing that can receive inflow from the SMCV. This is called the sphenoparietal sinus. San Millán Ruíz et al ${ }^{19}$ dispute this, stating that there is no connection of the SMCV along the lesser wing and that there is only a small dural sinus alone, which they call the dural sinus of the lesser wing. They also state that the SMCV can also run close to this area but has a separate connection to the cavernous sinus directly. Therefore, a fistula in the lesser sphenoid location could connect and drain in 2 ways. First, a fistula could connect either through the lesser wing sinus, which then drains into the cavernous sinus and its efferents, or perhaps through a connection to the meningeal emissary veins to the pterygoid venous plexus. However, if there is no direct connection, as stated by San Millán Ruíz et al, ${ }^{19}$ then direct cortical venous drainage from the lesser wing DAVF should not occur; rather, it would drain secondarily via the cavernous sinus. Second, a fistula could arise at the level of the lesser wing directly in connection with the SMCV (which can be anatomically close to or have an attachment at the lesser wing), which can then drain into both the cavernous sinus and other middle fossa cortical veins. The alternative classic description would be of a fistula of the sphenoparietal sinus, which has connections directly with both the cavernous sinus (or emissary outlets) and/or the SMCV.

At the greater wing region/floor of the middle cranial fossa, there are 2 other described connections of the SMCV, and these

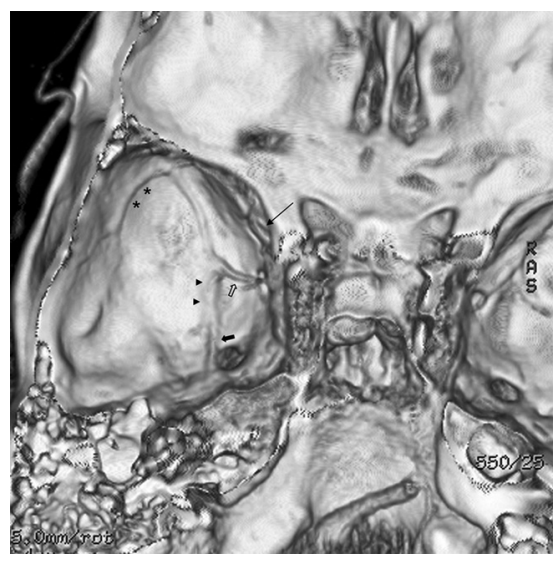

FIG 1. CT venogram reconstructon shows the typical locations of various sphenoidal group sinuses in the middle cranial fossa. The sinus is found along the lesser wing of sphenoid (long arrow). The sphenobasal sinus (arrowheads) and sphenopetrosal sinuses (asterisk) travel medially and laterally on the middle cranial fossa floor, respectively. They also have connections to the emissary veins of the foramen rotundum (solid arrow) and foramen ovale (open arrow).

are the sphenobasal and sphenopetrosal sinuses. Together, these have also been referred to as the paracavernous sinus, ${ }^{19-22}$ which is often considered the remnant of the embryonic tentorial sinus. The classic description is that the sphenobasal sinus drains inferiorly via emissary foramina into the pterygoid plexus, and the sphenopetrosal sinus courses laterally to reach the transverse sinus (Fig 1). As the SMCV is connected to the sphenobasal and sphenopetrosal sinuses, there will be resultant cortical venous drainage. Therefore, one might expect that fistulas involving the greater sphenoid wing would have a higher propensity for cortical venous drainage.

\section{Endovascular Technique}

All patients underwent endovascular treatment first. The goal of transarterial embolization was to occlude both the feeding arteries and the very proximal draining veins. Early in our experience, n-BCA mixed with Ethiodol (Savage Laboratories, Melville, New York) at 1:2 ratio was used. After approval by the US Food and Drug Administration for preoperative embolization of cerebral arteriovenous malformations, Onyx 34 and 18 (ev3, Irvine, California) became our preferred agents because the reflux-hold-reinjection technique allows deep and controlled penetration into the fistula and proximal draining vein. In high-flow fistulas, coils can be detached into higher flow shunts to better visualize and control flow before definitive transarterial occlusion with liquid embolic agents. If a patient experienced an unsuccessful transarterial embolization, or when anatomy was unsuitable for a transarterial approach, retrograde transvenous embolization was performed to obliterate the fistula and its recipient venous pouch with coils or Onyx.

\section{Surgical Technique}

If there is an incomplete fistula occlusion after endovascular therapy, surgical management of the remaining fistula is carried out. A pterional-skull base craniotomy is performed to expose the feeding arteries, cortical veins, and variceal pouch. The fistula is cured by coagulation of the feeding arteries, disconnection of the 
venous drainage, and resection of the lesion. Intraoperative angiography is often utilized.

\section{RESULTS}

\section{Angiographic Features}

In our series of angiograms, 5 patients had arteriovenous shunts involving the lesser wing of sphenoid and 6 patients had greater wing involvement. The clinical presentations and angiographic findings of these patients are summarized in On-line Table 1. DAVFs were supplied by multiple branches of the ICA and ECA in 7 patients, whereas DAVFs were supplied only by ECA branches in 4 patients. There were MMA branches supplying the fistula in all patients, with anterior MMA
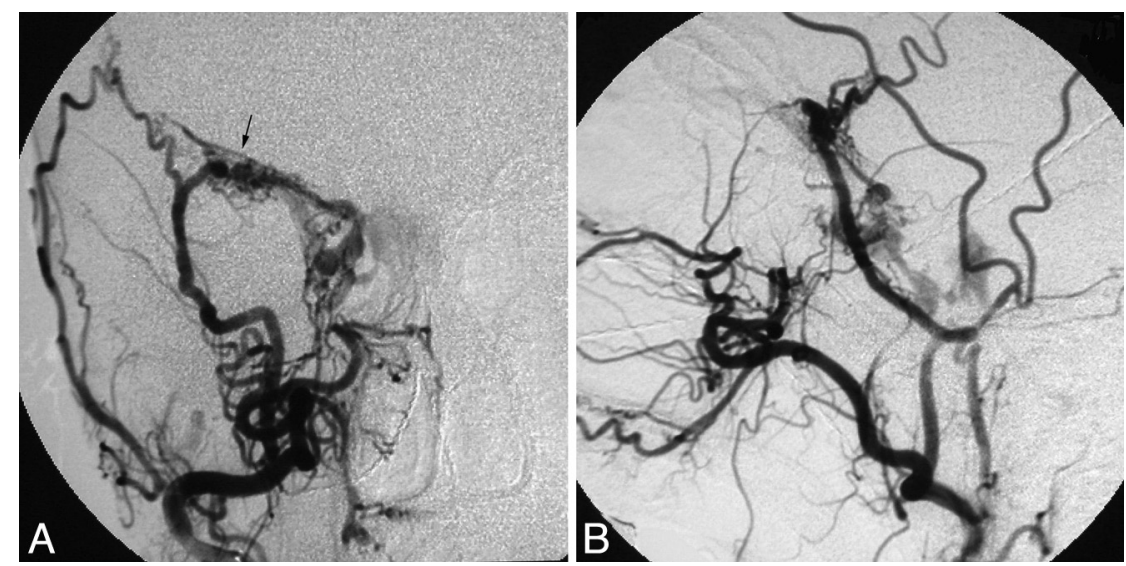

FIG 2. Patient 8. Cerebral angiograms show a fistula (arrow) along the lesser sphenoid wing, primarily fed by the right MMA and draining into the right cavernous sinus, bilateral inferior petrosal sinuses, and the right superior ophthalmic vein. $A$, Anteroposterior view of the right ECA angiogram. $B$, Lateral view of the right ECA angiogram. branches in 9 patients and petrosal MMA

branches in 2 patients. There were anterior MMA branches supplying the lesions in all 5 patients with lesser sphenoid wing fistulas and in 4 of 6 patients with greater sphenoid wing fistulas. There was an ICA dural arterial contribution in 7 patients, via the inferolateral trunk and/or the meningohypophyseal trunk supply in 6 patients, and a recurrent meningeal branch of the ophthalmic artery in 6 patients.

In patients with lesser wing fistulas, there was venous drainage into the lesser wing sinus in 4 patients and into the SMCV directly in 1 patient $(1 / 5,20 \%)$. The 4 patients with lesser wing sinus drainage then emptied into the cavernous sinus and SOV in 2 patients (Fig 2), posteriorly into the pterygoid plexus in 1 patient, and into a meningeal vein in 1 patient. The 1 fistula draining into the SMCV then drained into the vein of Labbe and transverse sinus as well as superiorly to the vein of Trolard and superior sagittal sinus in 1 patient. In the 6 patients harboring greater wing fistulas, 5 had venous drainage through the sphenobasal sinus, which then emptied into the cavernous sinus. The other patient had laterocavernous sinus opacification, which led to deep reflux into the basal vein of Rosenthal and, subsequently, the vein of Galen, the Sylvian vein, and the vein of Trolard into the superior sagittal sinus (Fig 3). Four greater wing fistulas connected with the SMCV $(4 / 6,66 \%)$.

Four patients had dangerous cortical venous drainage, 3 from greater sphenoid wing DAVFs $(3 / 6,50 \%)$ and 1 from a lesser sphenoid wing DAVF $(1 / 5,20 \%)$. There were varices secondary to venous hypertension or high-flow shunt surgery in all 6 patients with greater sphenoid wing DAVFs and in 1 patient with a lesser sphenoid wing DAVF. There was a higher frequency of varix in greater sphenoid wing DAVFs compared with lesser sphenoid wing DAVFs (100\% versus 20\%, $P=.02$; Fisher exact test).

\section{Transarterial Embolization}

Eight patients were primarily treated with transarterial ECA branch embolization using liquid embolic agents, most of which were fed by the branches of the MMA. $n$-BCA was used in 4 patients and Onyx was used in 4 patients. Four patients were felt to require an adjunctive coiling of the fistula and venous pouch to decrease any high-flow arterial input with coils before transarterial liquid embolic treatment. An anatomic endovascular cure was achieved in 6 patients. One of these patients needed an additional transvenous coil embolization via the facial vein and the SOV to achieve complete fistula obliteration. Endovascular therapy was partially successful in the remaining 2 patients, who were cured by microsurgical ligation of the fistulas.

\section{Transvenous Embolization}

Two fistulas were embolized transvenously with coils alone. The recipient venous pouch was retrogradely accessed through the facial vein and SOV in 1 patient, and through the straight sinus, vein of Galen, and vein of Rosenthal in the other. The third patient was treated with the combination of coils and Onyx via the inferior petrosal sinus approach. The varix was packed with Matrix coils (Boston Scientific, Fremont, California) and the sphenobasal sinus and fistula were occluded with Onyx. Additional transarterial MMA branch embolization with $n$-BCA or Onyx was completed in 2 of these patients to slow down arterial inflow before transvenous embolization. All patients had anatomic cures on immediate postprocedural angiograms.

\section{Surgical Treatment}

In the earliest 2 cases, surgical treatment was needed to obliterate the entire fistula after partial embolization. Pterional approaches were utilized in both patients, one with a lesser sphenoid wing DAVF and the other with a greater sphenoid wing DAVF. The enlarged feeding artery, the cortical vein, and the variceal pouch were exposed and ligated using microsurgical techniques. Any remaining MMA or ophthalmic artery feeders were then coagulated and clipped, and the enlarged pial veins and associated varices were separated from the fistulas in each case. The intraoperative angiograms showed that the fistulas were completely obliterated in both patients. The endovascular treatment, surgical treatment, and clinical outcomes are summarized in On-line Table 2.

\section{Outcomes and Follow-Up}

Asymptomatic stretched coil retention occurred in 1 patient (patient 1). There were no technical or significant clinical complica- 

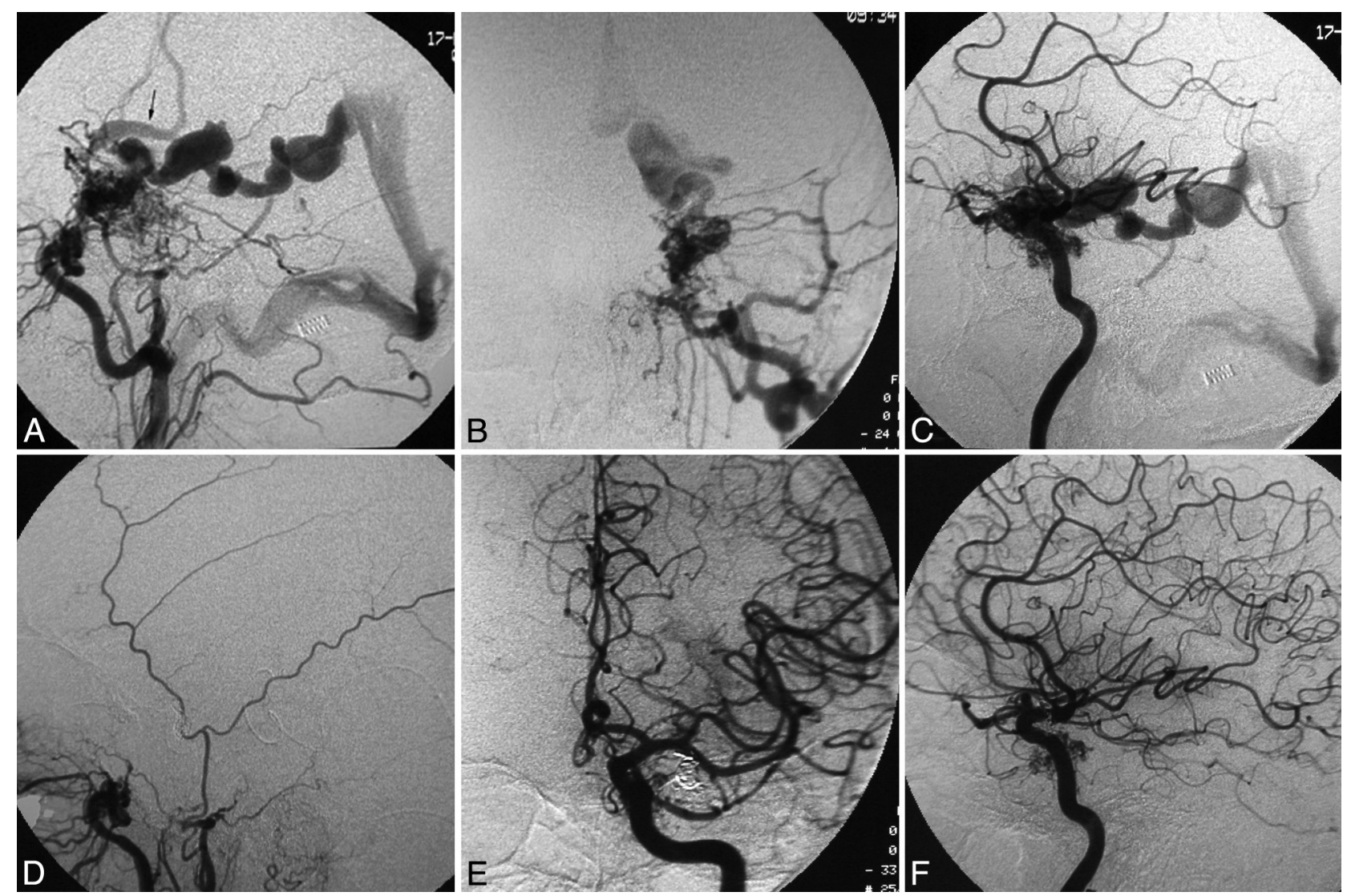

FIG 3. Patient 5 . The ECA ( $A$, lateral view; $B$, anteroposterior view) and ICA ( $C$, lateral view) angiograms show that the high-flow fistula is fed by multiple branches of the ICA and the ECA, and there is venous drainage into the basal vein of Rosenthal and subsequently the vein of Galen, as well as into the Sylvian and Trolard veins (arrow) into the superior sagittal sinus. A triaxial system with a guide catheter inserted into the internal jugular vein, an intervening Tracker-38 catheter (Boston Scientific) placed in the transverse sinus near the torcula—and, in this, a longer microcatheter was navigated to the exact fistula site through the straight sinus, the vein of Galen, and the basal vein of Rosenthal-and transvenous embolization of the fistula was performed using coils. Postembolization angiograms of the ECA $(D$, lateral view) and ICA $(E$, anteroposterior view; $F$, lateral view) show complete obliteration of the fistula.

tions in the other 10 patients. Eight patients had angiographic and clinical follow-up from 3 months to 7 years. All had anatomic cure and favorable clinical outcome.

\section{Illustrative Cases}

Patient 3. A 37-year-old woman presented with ocular symptoms and long-standing pulsatile tinnitus. Cerebral angiography revealed a high-flow single-channel fistula between the left MMA and a variceal sac at the left greater sphenoid wing, which drained into the left cavernous sinus. The petrosal outlets of the cavernous sinus were occluded; the only outflow path was the markedly dilated left SOV. An Echelon-10 microcatheter (ev3) was advanced to the fistula through the ipsilateral MMA, and a $4 \mathrm{~mm} \times 8 \mathrm{~cm}$ GDC coil (Boston Scientific) was detached at the junction of the most medial and distal venous sac (Fig 4A, $-B$ ). Subsequently, Onyx 34 was injected to plug the feeding artery behind the catheter tip and Onyx 18 was injected to penetrate the venous sac, working from distal to proximal to fill the coil mass at the junction of the left cavernous sinus back to the fistula. Occlusion of the cavernous sinus and its tributary veins and the proximal MMA was avoided by careful control of the Onyx injection. The fistula was then completely occluded and no evidence of fistula recurrence was noted at the 5-month angiographic follow-up (Fig 4C, -D).
Patient 11. A 66-year-old man experienced a progressive deterioration of his right visual acuity over a period of 8 months. Common carotid arteriography showed prior ligation of the right ECA, sparing only the ascending pharyngeal artery, and a DAVF arising along the right lesser sphenoid wing fed by the recurrent meningeal branch of the ophthalmic artery and the inferolateral trunk of the right ICA. There was early venous drainage via the vein of Labbe into the right transverse sinus, and a pial vein into the superior sagittal sinus. The right vertebral artery angiogram showed enlargement of the cervical collaterals, which reconstituted the occipital artery and also the internal maxillary artery and MMA, serving as primary feeding arteries (Fig $5 A-C$ ).

Multiple attempts at catheterization of the ophthalmic artery failed. The inferolateral trunk was then catheterized and two 2 $\mathrm{mm} \times 4 \mathrm{~cm}$ GDCs were placed to occlude this feeding artery. Embolization was completed with $n$-BCA through the right MMA. However, because small channels connected the MMA to the venous sac, there was insufficient penetration within the venous sac, which resulted in incomplete fistula occlusion (Fig 5D).

Because his visual deficit appeared to result from increasing pressure from a markedly enlarged ophthalmic artery, causing optic nerve compression, surgery was recommended. Right frontotemporal craniotomy was performed. The right optic nerve was 

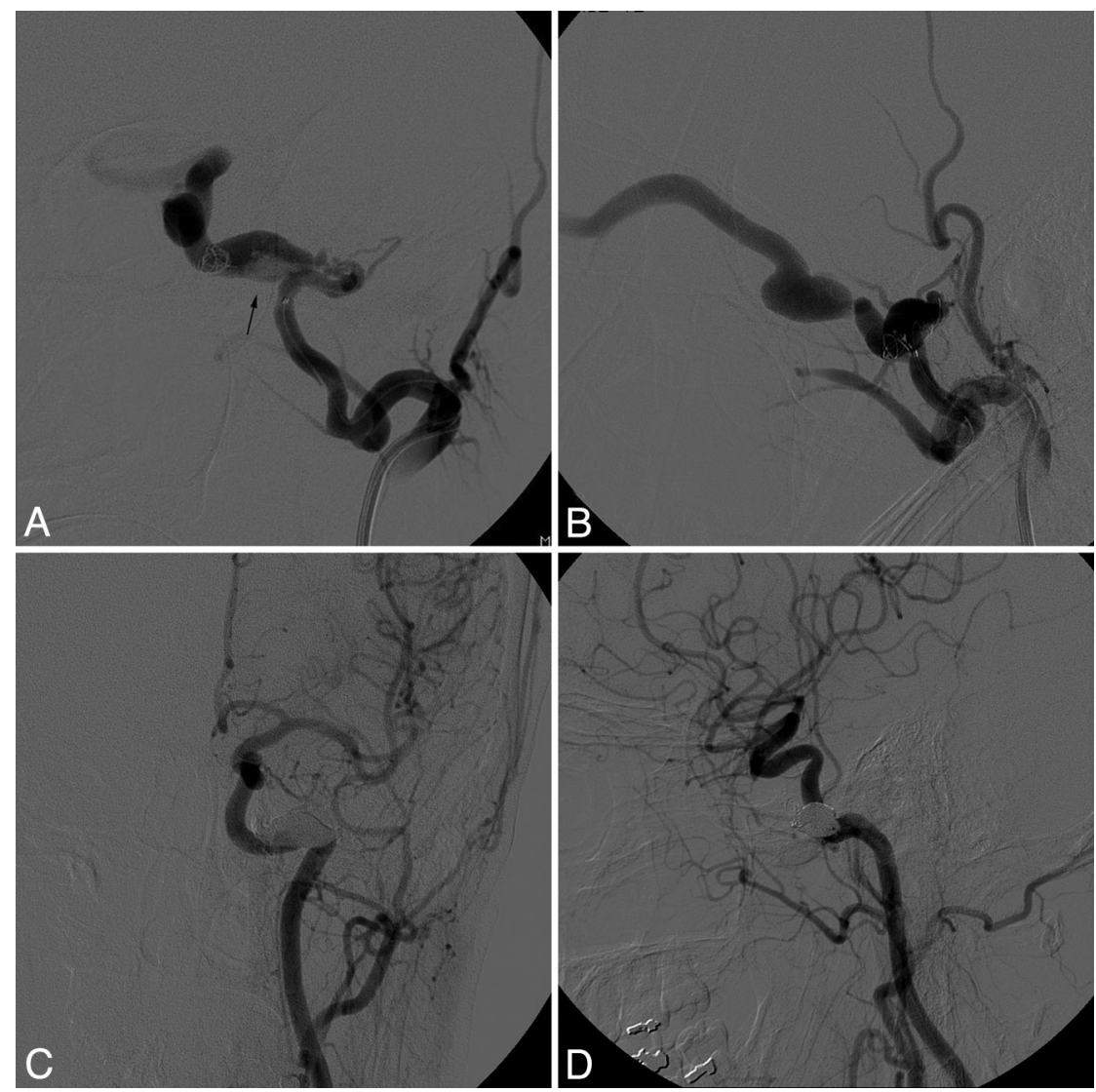

FIG 4. Patient 3 . Anteroposterior $(A)$ and lateral $(B)$ view of the left ECA angiograms during transarterial coil embolization show that the fistula site involves the sphenobasal sinus (arrow) draining to the left cavernous sinus and SOV. Five-month follow-up angiogram of the left common carotid artery ( $C$, anteroposterior view; $D$, lateral view) demonstrates durable complete obliteration of the fistula by Onyx and coils.

markedly compressed from below by a knuckle within the enlarged ophthalmic artery. The ophthalmic artery was clipped after incising the optic nerve dural sheath. The venous connections between the fistula and the right temporal lobe were coagulated and disconnected. The fistula along the superior orbital fissure was coagulated and excised. Intraoperative angiography demonstrated no obvious filling of the fistula. At an 18-month follow-up, cerebral angiography showed no evidence of recurrent fistula (Fig $5 E,-F)$, and the patient remained asymptomatic.

\section{DISCUSSION}

The sphenoidal dura extends laterally from the central sphenoid body to cover the 2 sets of greater and lesser sphenoid wings and, inferiorly, the pterygoid processes. DAVFs within the greater and lesser sphenoid wings have vascular features distinctive from the cavernous sinus DAVFs within the parasellar dura, which are the most common type of DAVFs of the middle cranial fossa.

Both the ICA and ECA give rise to multiple branches, which supply the dural territories of the sphenoid wings. The arterial contributories of the sphenoid wings arise predominantly from the MMA, accessory meningeal artery, artery of foramen rotundum, middle temporal artery, anterior auricular artery, and inferolateral trunk and meningohypophyseal trunk of the cavernous ICA, as well as recurrent meningeal branches of the ophthalmic artery. Seven DAVFs in our series received multiple arterial contributories, and the MMA was the main feeding artery in all patients.
Anatomically, the sphenoidal group of cerebral veins, formed by the terminal ends of the superficial Sylvian and occasionally the deep Sylvian veins, drain into the sphenoparietal or cavernous sinus and, less commonly, into the sphenobasal or sphenopetrosal sinuses that course on the inner surface of the sphenoid bone. ${ }^{23,24}$ DAVFs of the lesser sphenoid wing are often considered to be abnormal connections between the MMA and the sphenoparietal sinus, occasionally resulting from traumatic fractures of the skull or after extended craniotomies. ${ }^{3,6,7,9,17}$ However, other authors have implied that the sphenoparietal sinus may represent an artificial combination of 2 venous structures - the parietal portion of the anterior branch of the middle meningeal veins and a dural channel located under the lesser sphenoid wing, the sinus of the lesser sphenoid wing. They suggested that the SMCV drains into the paracavernous sinus (laterocavernous sinus or the combination of the sphenobasal and sphenopetrosal sinuses) or the cavernous sinus rather than the venous structures described here in association with the lesser sphenoid wing. ${ }^{19,20}$

From our series of superselective angiograms in patients with DAVFs, the fistula sites occupy the dura of the lesser or greater sphenoid wings, which then drain into the adjacent dural sinuses. The cavernous sinus and SOV were involved in 6 patients. These patients had symptoms similar to those seen in cavernous DAVFs. The venous drainage was posteriorly routed into the pterygoid plexus in 1 patient who complained of pulsatile tinnitus. In contrast to the more benign sphenoparietal sinus (lesser wing) 

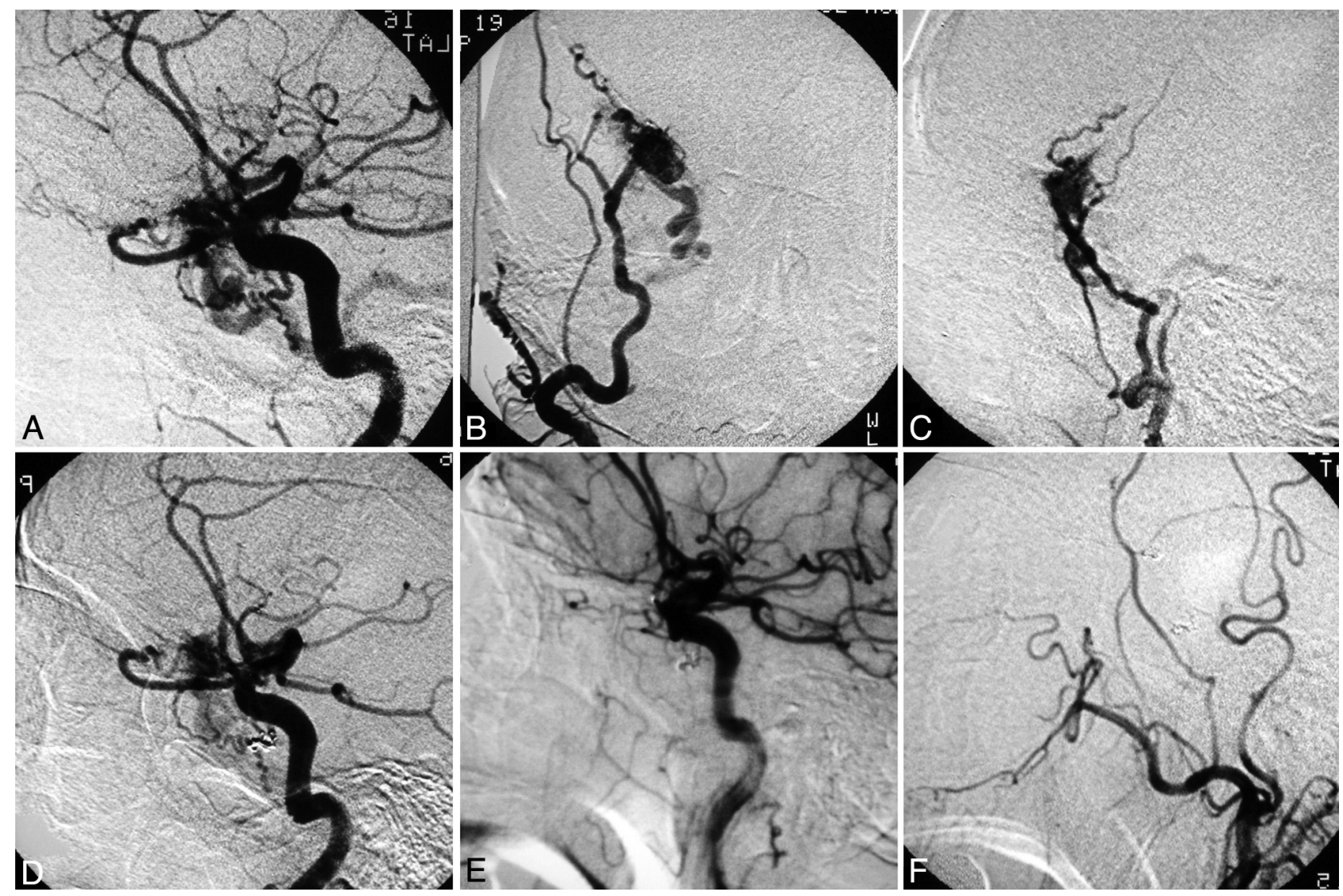

FIG 5. Patient 11. Lateral angiographic view of the right ICA $(A)$ shows primary feeding arteries from the recurrent meningeal branch of the ophthalmic artery as well as the inferolateral trunk of the ICA, with resultant venous drainage into an enlarged vein of Labbe. Anteroposterior $(B)$ and lateral $(C)$ view of the right internal maxillary artery angiogram showing a fistula at the lesser sphenoid wing draining into the right temporal lobe cortical vein. Lateral view of the ICA $(D)$ after transarterial coiling and $n-B C A$ injection of the fistula showing a residual lesion. Lateral view of the right ICA $(E)$ and ECA $(F)$ at 18-month follow-up show complete obliteration of the fistula.

DAVFs with cortical venous drainage in only $20 \%$, the sphenobasal sinus (greater wing) DAVFs more likely drained into the SMCV (66\%), with cortical venous drainage in $50 \%$ and variceal formation in $100 \%$ of these sphenobasal lesions. Therefore, the greater wing lesions may significantly increase the risk of intracranial hemorrhage. ${ }^{12,15,25}$

Geibprasert et $\mathrm{al}^{26}$ and other researchers have characterized the sphenoidal DAVFs as ventral epidural, or osteo (cartilaginous)-epidural. They further state that these lesions would normally have epidural efferents, which could therefore avoid cortical venous reflux, except in cases where those epidural efferents were thrombosed. ${ }^{1,8}$ In our series, a predilection for cortical venous reflux is seen in the fistulas located in the greater sphenoid wing. Presumably, close approximation and capacitance of the cavernous sinus (less likelihood of immediate redirection into cortical veins because of its many outlets and resultant earlier symptomology with orbital symptoms) to lesser wing DAVFs led to the diagnosis before any establishment of cortical venous reflux. Conversely, greater wing DAVFs have presumably more tenuous connections to their epidural drainage (including the cavernous sinus), and close connection with the paracavernous sinus (confluence of the sphenobasal and sphenopetrosal sinuses) which communicates with the SMCV, which results in earlier cortical venous reflux and/or later diagnosis because of a relative lack of early ocular symptoms.
In our series, 4 patients had cortical or deep venous drainage, 3 had DAVFs at the greater sphenoid wing, and 1 at the lesser sphenoid wing. One bled parenchymally. The subgroup of patients with DAVFs presenting without hemorrhage or nonhemorrhagic neurologic deficits may have a less aggressive clinical course. $^{27}$

Because some sphenoidal DAVFs (especially those at the greater wing) have cortical venous drainage, venous hypertension, retrograde sinus flow, or Galenic drainage, treatment should be strongly considered and aimed at complete fistula occlusion; that is, the occlusion of the most proximal venous recipient pouch. In the current era of Onyx for curative embolization of DAVFs, transarterial endovascular occlusion of fistulous connections is the primary treatment technique. ${ }^{28-30}$ Transvenous embolization continues to be a safe and effective option if the fistula sites can be approached via an amenable venous pathway, such as the inferior petrosal sinus, facial vein, or the vein of Galen. Incomplete fistula occlusion or cavernous sinus packing alone should be avoided because of potential dangerous flow diversion into cortical or deep veins. Flow control using coils, acrylics, or temporary balloon occlusion is useful for high-flow shunts to decrease the likelihood of distal embolic migration and to improve the penetration of embolic material into the arteriovenous connections. ${ }^{29}$

In this series, 9 of 11 patients were cured by endovascular means. Four had curative embolization through a transvenous 
approach utilizing coils alone or in combination with Onyx. In the first 4 cases in this series, we used low concentration $n$-BCA under flow-arrest conditions to reach the shunt and to penetrate the origin of the draining vein, as has been well described in the literature. ${ }^{13}$ With the use of Onyx embolic agent, we achieved anatomic cure in 4 patients by using transarterial Onyx embolization. This promising transarterial Onyx-based embolization of DAVFs involving the lesser sphenoid wing has been described in a case report. ${ }^{14}$ DAVF involving the laterocavernous sinus along the greater wing of the sphenoid, which used to be treated with transvenous coiling, can be occluded with transarterial Onyx embolization as well. ${ }^{31}$

When embolizing the MMA branches with Onyx, the occlusion of the cavernous and petrosal branches may result in ischemic injury to the trigeminal or facial nerves. Care should be taken to avoid reflux of Onyx to the foramen spinosum.

In our series, 2 patients with incompletely embolized DAVFs were subsequently cured by surgical disconnection of the fistula via pterional and extended skull-base craniotomies. In a study of 53 high-grade intracranial DAVFs treated with surgery, 3 patients with sphenoparietal sinus DAVFs had complete obliteration by a pterional approach. ${ }^{32}$ Microsurgery remains a useful option for obliterating DAVFs of the sphenoid wings with cortical venous reflux after unsuccessful embolization. A surgical interruption of the arterialized draining vein can be effectively used to completely obliterate the DAVF as it exits the dura, unless it drains through cortical veins alone. The inadvertent rupture of a varix before disconnecting the cortical veins should be avoided, and a more extensive surgical exposure at the skull base is often useful for minimizing this risk. ${ }^{15}$ Radical excision of the fistula is considered unnecessary in most cases.

\section{CONCLUSIONS}

Dural arteriovenous fistulas may occur within the dura of the greater and lesser sphenoid wings. Lesser-sphenoid-wing DAVFs have a lower likelihood to recruit cortical venous drainage directly, but more often drain into the cavernous sinus and therefore can present like cavernous sinus DAVFs. Rarely, these can connect to the SMCV directly and therefore have cortical venous drainage. Greater-sphenoid-wing DAVFs always connect to the SMCV, and all of our cases had varices secondary to venous hypertension and/or high flow, and 3 of 6 patients had cortical venous drainage, so their differentiation has clinical significance. Curative endovascular occlusion of the fistulous connections through a transarterial or transvenous approach is the primary therapeutic strategy, particularly through transarterial Onyx embolization. Surgical disconnection of cortical draining veins can be considered when embolization is unsuccessful.

Disclosures: Reza Jahan-Research Support (including provision of equipment or materials): Talecris Biotherapeutics, Details: Research support; Consultant: ev3, Details: Consultant. Neil A. Martin-Consultant: Global Care Quest/Karl Storz Endoscopy America, Details: Consulting as Chief Medical Officer, advising regarding outpatient electronic patient portals and clinic EMR, healthcare IT. Gary DuckwilerSpeaker Bureau: Concentric Medical, Details: Occasionally give talks at user's group meetings; Consultant: Concentric Medical, Details: Scientific advisor; Ownership Interest: Concentric Medical, Details: Minor stockholder.

\section{REFERENCES}

1. Sarma D, ter Brugge K. Management of intracranial dural arteriovenous shunts in adults. Eur J Radiol 2003;46:206-20

2. Fincher EF. Arteriovenous fistula between the middle meningeal artery and the greater petrosal sinus; case report. Ann Surg 1951;133:886-88

3. Pakarinen S. Arteriovenous fistula between the middle meningeal artery and the sphenoparietal sinus. A case report. J Neurosurg 1965;23:438-39

4. Ishii M, Suzuki S, Iwabuchi T. Dural arteriovenous malformation with false aneurysm and exophthalmos. A successfully treated case. Acta Neurochir (Wien) 1978;43:101-10

5. Bitoh S, Arita N, Fujiwara M, et al. Dural arteriovenous malformation near the left sphenoparietal sinus. Surg Neurol 1980;13:345-49

6. Smith JE, Epps J, Press HC Jr, et al. Traumatic arteriovenous fistula between the middle meningeal artery and the sphenoparietal sinus: a case report and review of the world literature. J Natl Med Assoc 1981;73:274-78

7. Freckmann N, Sartor K, Herrmann HD. Traumatic arteriovenous fistulae of the middle meningeal artery and neighbouring veins or dural sinuses. Acta Neurochir (Wien) 1981;55:273-81

8. Piske RL, Lasjaunias P. Extrasinusal dural arteriovenous malformations. Report of three cases. Neuroradiology 1988;30:426-32

9. Tsutsumi K, Shiokawa Y, Kubota M, et al. Postoperative arteriovenous fistula between the middle meningeal artery and the sphenoparietal sinus. Neurosurgery 1990;26:869-71

10. Ezura M, Takahashi A, Mizoi K. Dural arteriovenous shunts involving the sphenoparietal sinus: a case report. Interv Neuroradiol 1996;2:223-28

11. Watanabe T, Matsumaru Y, Sonobe M, et al. Multiple dural arteriovenous fistulae involving the cavernous and sphenoparietal sinuses. Neuroradiology 2000;42:771-74

12. Nomura S, Anegawa S, Nakagawa S, et al. Subarachnoid hemorrhage caused by dural arteriovenous fistula of the sphenobasal sinuscase report. Neurol Med Chir (Tokyo) 2002;42:255-58

13. Nelson PK, Russell SM, Woo HH, et al. Use of a wedged microcatheter for curative transarterial embolization of complex intracranial dural arteriovenous fistulas: indications, endovascular technique, and outcome in 21 patients. J Neurosurg 2003;98:498-506

14. Rezende MT, Piotin M, Mounayer C, et al. Dural arteriovenous fistula of the lesser sphenoid wing region treated with Onyx: technical note. Neuroradiology 2006;48:130-34

15. Zhou LF, Chen L, Song DL, et al. Dural arteriovenous fistula of the sphenobasilar sinus with concomitant meningioma: case report and review of the literature. Neurosurg Rev 2007;30:269-74

16. Cohen JE, Gomori JM, Grigoriadis S, et al. Dural arteriovenous fistula of the greater sphenoid wing region in neurofibromatosis type 1. Pediatr Neurosurg 2008;44:172-75

17. Unterhofer C, Chemelli A, Waldenberger P, et al. Traumatic fistula between the middle meningeal artery and the sphenoparietal sinus. Acta Neurochir (Wien) 2009;151:1301-04

18. Khadavi NM, Mancini R, Nakra T, et al. Rare dural arteriovenous fistula of the lesser sphenoid wing sinus. Ophthal Plast Reconstr Surg 2009;25:404-06

19. San Millán Ruíz D, Fasel JH, Rüfenacht DA, et al. The sphenoparietal sinus of Breschet: does it exist? An anatomic study. AJNR Am J Neuroradiol 2004;25:112-20

20. San Millán Ruíz D, Oka M, Fasel JH, et al. Transvenous embolization of a dural arteriovenous fistula of the laterocavernous sinus through the pterygoid plexus. Neuroradiology 2007;49: 665-68

21. Suzuki Y, Matsumoto K. Variations of the superficial middle cerebral vein: classification using three-dimensional CT angiography. AJNR Am J Neuroradiol 2000;21:932-98

22. Tanoue S, Kiyosue H, Okahara M, et al. Para-cavernous sinus venous structures: anatomic variations and pathologic conditions evalu-

AJNR Am J Neuroradiol 34:373-80 Feb 2013 www.ajnr.org

379 
ated on fat-suppressed 3D fast gradient-echo MR images. AJNR Am J Neuroradiol 2006;27:1083-89

23. Tubbs RS, Salter EG, Wellons JC 3rd, et al. The sphenoparietal sinus. Neurosurgery 2007;60:ONS9-12

24. Rhoton AL Jr. The cerebral veins. Neurosurgery 2002;51:S159-205

25. Sakata $\mathrm{H}$, Nishimura $\mathrm{S}$, Mino M, et al. Serial angiography of dynamic changes of traumatic middle meningeal arteriovenous fistula: case report. Neurol Med Chir (Tokyo) 2009;49:462-64

26. Geibprasert S, Pereira V, Krings T, et al. Dural arteriovenous shunts: a new classification of craniospinal epidural venous anatomical bases and clinical correlations. Stroke 2008;39:2783-94

27. Strom RG, Botros JA, Refai D, et al. Cranial dural arteriovenous fistulae: asymptomatic cortical venous drainage portends less aggressive clinical course. Neurosurgery 2009;64:241-47
28. van Rooij WJ, Sluzewski M. Curative embolization with Onyx of dural arteriovenous fistulas with cortical venous drainage. $A J N R$ Am J Neuroradiol 2010;31:1516-20

29. Shi ZS, Loh Y, Duckwiler GR, et al. Balloon-assisted transarterial embolization of intracranial dural arteriovenous fistulas. J Neurosurg 2009;110:921-28

30. Shi ZS, Ziegler J, Gonzalez NR, et al. Transarterial embolization of clival dural arteriovenous fistulae using liquid embolic agents. Neurosurgery 2008;62:408-15

31. Lv X, Jiang C, Li Y, et al. Endovascular treatment of dural fistulas with the venous outflow of laterocavernous sinus. Eur J Radiol 2010;75:e129-34

32. Kakarla UK, Deshmukh VR, Zabramski JM, et al. Surgical treatment of high-risk intracranial dural arteriovenous fistulae: clinical outcomes and avoidance of complications. Neurosurgery 2007;61:447-57 